\title{
Improving the Examination System of Medical Non-Degree Courses in Provincial Universities
}

\author{
Jiangang Wang \\ Medical College \\ Henan University of Science and Technology \\ Henan Province, China \\ Ling Liu \\ Medical College \\ Henan University of Science and Technology \\ Henan Province, China
}

\author{
Lengxin Duan \\ Medical College \\ Henan University of Science and Technology \\ Henan Province, China \\ Ruifang Li \\ Medical College \\ Henan University of Science and Technology \\ Henan Province, China
}

\begin{abstract}
The improvement of the non-degree curriculum assessment system is conducive to the standardization of the teaching behavior of the teachers, which is beneficial to the cultivation of the postgraduate students' creative ability, and which is beneficial to the correct evaluation of the postgraduate students' academic level. The non-degree courses are divided into three categories, namely, the professional knowledge class, the subject progress class and the scientific research skill class. Through the implementation, the innovative consciousness and the innovation ability of the graduate students are preliminarily improved, and the aim of objective evaluation can be achieved.
\end{abstract}

Keywords: Examination System, Non-Degree Courses, Innovative Ability, Postgraduate Students

Non degree courses refer to professional elective courses, which are offered by related majors for graduate students, including experimental skills training courses selected according to research directions and related disciplines, Frontiers knowledge courses, research design and thesis writing skills courses, etc. Degree courses can develop the basic abilities of graduate students, while non-degree courses develop graduate research skills and innovative abilities. Therefore, we should strengthen the management of non-degree courses, because it is an indispensable link to ensure the training quality of graduate students, especially to improve their scientific research skills and innovation ability. On the level of the college of University [1], it is imperative to perfect the examination system of non-degree courses.

\section{THE NECESSITY OF PERFECTING THE EXAMINATION SYSTEM OF NON-DEGREE COURSES}

A. Perfecting the Evaluation System of Non-Degree Courses is Conducive to Standardizing the Teaching Behavior of Teaching Teachers.

In general, the examination of "English" and "Politics" in the public compulsory courses in degree courses is organized by the University, and the examination of the basic theory and professional knowledge is often arranged by the College. The teacher is responsible for the assessment of non-degree courses. From the actual situation at present, the management of non-degree courses in colleges and even disciplines is rare. That is, the assessment of the non - degree course is the responsibility of the teaching teacher, and the teaching effect and the teaching quality are completely related to the teacher's level and sense of responsibility. Some teachers do not pay attention to what graduate students need to learn, and part of the knowledge that they teach is the repetition or continuation of the undergraduate course [2]. Therefore, the examination requirements of non-degree courses are relatively loose, often cannot play a role of supervision, diagnosis and correct evaluation, and also cannot significantly improve the innovative ability of graduate students. Therefore, it is necessary to establish or perfect the evaluation system of non-degree courses for postgraduates.

B. Perfecting the Examination System of Non-Degree Courses is Beneficial to the Cultivation of Graduate Students' Innovative Ability.

Ability is the quality embodied in accomplishing a goal or task, and people show different abilities in completing activities, and ability directly affects the efficiency of activities. The innovation refers to the existing thinking mode, which is different from the traditional or ordinary thinking. The core of graduate training is the cultivation of scientific research and innovation ability. Most of the non-degree courses are related to the cultivation of innovation ability, but the improvement of innovation ability is affected by many factors, including tutors' pressure, schoolmate's pressure, incentives and policy equity [3]. Therefore, perfecting the examination system of non-degree courses is beneficial to the cultivation of graduate students' innovative ability.

\section{Perfecting the Examination System of Non-Degree Courses is Beneficial to the Correct Evaluation of Students' Academic Level.}

The evaluation of graduate students' academic level during the first grade curriculum study mainly depends on the curriculum assessment, and the result of the curriculum assessment will affect the evaluation of the 
scholarship. Scholarships are a common way for schools to motivate students to work hard and develop across the board [4]. At present, scholarships are generally awarded to graduate students in China, but the scholarship is hierarchical, and the division of the grade in the first grade is mainly based on the results of curriculum assessment. Because of the variety of non-degree courses, different majors and even different specialties choose different courses for graduate students in the same direction. The number of students selected for each course is small and the number of teachers taught is large. If the assessment is not standardized, it will affect students' course grade and then affect the evaluation of student scholarships, and even affect other aspects.

\section{FULLY UNDERSTAND THE CONTENT AND FUNCTION OF NON-DEGREE COURSES AND MAKE A GOOD CLASSIFICATION OF COURSES}

There are 34 elective courses (non-degree courses), which are available for medical and related graduate students, including Medical Specialties English, Medical Molecular Genetics, Molecular Biology, Human Section Anatomy, Neuroanatomy, Pharmacotherapeutics, Clinical Epidemiology, Neurophysiology, Medical Molecular Biology Technology, Methods of Medical Scientific Research and Paper Writing, Histopathological Technique, Advances in Oncology, Advances in Physiology, Advanced Pharmacology, and so on, offered in the medical college of Henan University Of Science and Technology. On the basis of the above Content analysis, these courses can be divided into three categories: one is the professional knowledge of the research direction, the other is the progress of the subject, and the third is the scientific research skills. Different assessment methods should be selected according to different types of courses.

\section{TO DETERMINE THE FORM OF EXAMINATION ACCORDING TO THE CATEGORY OF COURSES}

The examination of academic achievement of professional knowledge courses is based on the score of examination paper. The examination of basic courses in professional direction refers to the examination of degree courses, in which examination papers account for $70 \%$ $80 \%$ of the total scores, but the proportion of the new knowledge content is higher, and we should consider the usual results, such as answering questions, practicing homework, attendance rate.

The examination of the course of Scientific Research skill is based on the skill test. The assessment of scientific research skill courses, such as Methods of Medical Scientific Research and Paper Writing, Establishment and Diagnosis of Animal Model of Disease, Medical Molecular Biology Technology, is mainly based on ordinary skill training. Achievement score is assessed by the results of skill manipulation and skill improvement, which should account for $60 \%$. Scientific research skills also involve theoretical knowledge and concepts, which are tested in writing $[5,6]$, and this proportion accounts for $40 \%$ of the assessment results.
The examination of the subject progress courses is mainly the writing of summary papers. In the subject progression course, such as Advances in Physiology, Advanced Pharmacology, Progress in Pathophysiology, graduate students can write a summary of their own research direction to understand the progress of the subject. The requirement of summary paper is to stop downloading directly on the Internet, and let graduate students understand new content and new progress around the topic selection. The teacher must carefully check the content of the summary, and they can combine with their instructors to evaluate its level, and the form of group discussions, graduate students should use PPT to report to everyone, including students and other teachers, and let the subject mentors make a collective evaluation. At the same time, they can communicate with each other, which plays the role of learning from each other (this part can account for $60 \%$ of the total score). In addition, at least 10 new nouns and new concepts of the progress of the subject are examined in the examination paper (score is $40 \%$ ) in order to promote a more comprehensive understanding of the progress of the subject in question.

\section{IMPLEMENTATION MEASURES OF CURRICULUM EXAMINATION SYSTEM}

There must be rules and regulations to perfect the examination system of medical non-degree courses [7]. The system can be carried out by making modules of different kinds of courses, timely training of teachers, supervising of graduate teaching offices or graduate secretaries. Through the implementation of recent years, our college has solved some problem, i.g. that the examination requirements of non-degree courses are not strict and unable to play a learning-oriented role, and that evaluation does not reflect the real level of postgraduate study, At the same time, the innovation consciousness and ability of graduate students are improved, and the objective evaluation can be achieved. Of course, the assessment system of postgraduate courses should be constantly improved according to different requirements of the times.

\section{ACKNOWLEDGEMENT}

Graduate Education Reform Project of Henan University of Science and Technology No. 2015YJG-005

\section{REFERENCES}

[1] P.W.Wang, Thoughts on Optimizing the Tertiary Management of Graduate Education in Our University, Journal of Guangdong Medical College. 26(2008) 319-320.

[2] F.L.Qin Wang H, C.X.Hu, Problems in Graduates Curricula Teaching and Countermeasures,Journal of Huazhong Agricultural University (Social Sciences Edition).6(2007)148-150.

[3] X.R. Gao, Q. Wan, Y.Chen, The Factors Affecting the Improvement of Postgraduates'Research Ability and Their Mechanism, Jourmal of Higher Education Managemrnt. 9(2015) 114-117.

[4] G.Xu, H.B.Ma, Several problems on graduate studies scholarship in the implementation process, Degree and Graduate Education. 12(2015)27-32.

[5] R.L.Wu, J.Z.Wang. Research-based Teaching and the cultivation of Graduate students'Innovative ability, Degree and Graduate Education. 3(2013)10-15. 
[6] J.Y. Tao, S.Q. Kuang, D.X.Yang, Exploration on Postgraduate Practice Teaching System with Innovation-oriented, Research and Exploration in Laboratory, 32(2013)317-320.

[7] L.H.Ma, Exploration and Practice of Postgraduate course Construction in Provincial Colleges and Universities, Degree and Graduate Education. 10(2017)24-28. 